\title{
山西资源型城市创新环境与产业结构转型空间耦合
}

\author{
姜海宁 ${ }^{1,2}$, 张文忠 ${ }^{2}$, 余建辉 ${ }^{2}$, 张建伟 ${ }^{3}$ \\ (1. 浙江师范大学地理与环境科学学院, 金华 $321004 ; 2$. 中国科学院地理科学与资源研究所, 区域可持续发 \\ 展分析与模拟重点实验室, 北京 $100101 ; 3$. 安阳师范学院资源环境与旅游学院,安阳 455000)
}

\begin{abstract}
摘要：通过构建耦合协调度模型, 分析 2003 年和 2016 年山西资源型城市创新环境与产业结构 转型的空间耦合关系。结果表明:不同优势的城市创新环境质量随着时间的推移均发生不同 程度的变化, 其中高水平创新环境骤降, 中等水平稳步升高, 而低水平创新环境并未实现突破 性的提升; 产业结构高级化指数均呈增大趋势, 产业结构合理化指数较高且变化相对复杂; 原 创新环境与产业结构高级化、合理化耦合度指数均较高且均为高度耦合区, 但随着时间的推 移, 大部分城市逐渐下降; 协调发展度较低, 整体始终表现为“南北中度失调、中间严重失调” 的 格局; 大部分城市相对发展度指数逐渐上升, 山西 “南北” 区域属于创新环境超前型或同步发展 型, 而“中间”区域主要为创新环境滞后型的格局并未发生显著变化。因此,应当充分依托城市 创新环境或产业结构转型现有的优势, 因地制宜地分类指导其资源型城市建设发展, 从而实现 创新环境与产业结构转型的并进协同发展。
\end{abstract}

关键词：创新环境;产业结构转型;空间耦合;资源型城市;山西

资源型城市是依托资源开发而兴建或发展，并以资源开采及其加工为主导产业的城

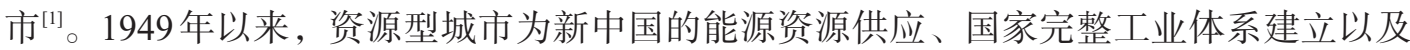
国民经济的快速发展做出了重要的历史性贡献 ${ }^{[2,3]}$ 。尽管如此，随着经济的快速发展，资 源型城市发展也相继出现了资源濒临枯竭、生态环境日益恶化、接续产业发展乏力、失 业率上升等诸多经济社会环境问题，亟待进行产业结构转型。国务院制定的《国家中长 期科学和技术发展规划纲要（2006-2020）》明确指出, 要把提高自主创新能力作为调整 经济结构、转变增长方式、提高国家竞争力的中心环节。区域自主创新能力的提高取决 于良好的区域创新环境，而且区域创新环境对产业及整个区域的发展具有持续的推动作 用 ${ }^{[4]}$ ，如德国鲁尔、美国休斯敦、法国洛林、日本九州等资源型城市产业转型实践证明， 资源型城市产业结构转型离不开区域创新环境的建设与完善[]。加快产业结构转型是促使 资源型城市尽快摆脱困境的关键 ${ }^{[6]}$, 因而亟需优化区域创新环境, 加快产业结构转型, 从 而实现资源型城市经济社会的健康持续发展。目前针对创新环境与产业结构转型方面的 研究成果均很丰富, 其中国外对创新环境研究较早, 1985 年欧洲创新研究小组便对创新 环境概念进行界定 ${ }^{[7]}$ 。随后研究日益多元化, 集中于创新环境的构成 ${ }^{[8,9]}$ 、评价 ${ }^{[10]}$ 以及创新 环境对创新能力 ${ }^{[1]]}$ 、企业（集群）、产业或高校创新绩效 ${ }^{[12-15}$ 的影响等方面研究，但专门针 对资源型城市创新环境方面研究很少, 如谢远涛等 ${ }^{[160}$ 以我国 116 个资源型地级城市数据为

收稿日期：2018-12-04；修订日期：2019-09-05

基金项目：国家自然科学基金项目（41971160，41871170，41771174); 浙江省自然科学基金项目（LY19D010009）美 丽中国生态文明建设科技工程专项（XDA23100302）

作者简介: 姜海宁 (1982- ), 男, 江苏徐州人, 博士, 副教授, 研究方向为经济地理。E-mail: jhn841263@163.com 通讯作者：张文忠 (1966-), 男, 内蒙古呼和浩特人, 研究员, 博士生导师, 研究方向为城市与区域发展。

E-mail: zhangwz@igsnrr.ac.cn 
研究对象, 认为我国资源型城市的创新环境水平较低。总体来说, 已有针对区域创新环 境方面的研究成果主要来自于经济学、管理学方面的学者, 而基于地理学视角对此关注 较少, 且主要探讨区域创新环境对企业的根植性与区位选择影响 ${ }^{[17,18]}$ 。与之相比, 国外针对 资源型城市产业结构转型方面的研究较多, 以 20 世纪 30 年代加拿大 Innis H A 为代表的 西方学者对此领域做出了开创性工作, 且在实践方面, 国外资源型城市转型成功与失败 的典型案例分别以德国鲁尔区、俄罗斯巴库为代表进行分析 ${ }^{[19]}$ 。而国内学者对此关注较 晚, 并主要以国内典型资源型城市或区域为案例, 对其产业结构转型的对策 ${ }^{[20] 、}$ 战略重

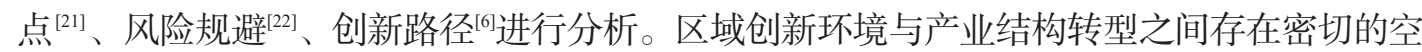
间耦合关系，已有研究从区域创新环境与新兴产业成长 ${ }^{[23]}$ 、企（产）业创新绩效 ${ }^{[4,24]}$ 、研发 产业集聚 ${ }^{[18]}$ 等方面关系展开分析, 或者探讨基础设施环境、制度环境等创新环境某个维 度与产业结构转型之间的关系等 ${ }^{[25,26]}$, 而这些正是区域创新环境与产业结构转型耦合关系 的具体表现，并已得到证实，但专门针对资源型城市创新环境与产业结构转型的空间耦 合关系研究未有涉及, 这也使得资源型城市创新环境与产业结构转型间的良性互动成为 理论研究和区域发展呆待解决的重要问题之一。2013 年12月 3 日, 国务院出台了《全国 资源型城市可持续发展规划（2013-2020年）》。而作为典型煤炭资源型城市最多的省 份，山西省除省会城市太原外，其余 10 个地级市（大同、朔州、忻州、阳泉、晋中、吕 梁、临汾、长治、运城和晋城）均为资源型城市，其中朔州为成长型资源型城市，其他 9市均为成熟型资源型城市, 且同样面临资源型城市所不可避免的经济社会环境问题, 而这与区域创新环境与产业结构转型的空间关系不耦合密切相关。因此, 选择较具代表 性与示范价值的山西省为研究区域, 探讨其资源型城市创新环境与产业结构转型的空间 耦合关系, 希冀为山西省以及全国其他地区资源型城市创新环境与产业结构转型的并进 协同发展提供理论参考与决策依据。

\section{1 创新环境与产业结构转型的空间耦合机理}

区域创新环境与产业结构转型存在密切的动态互动机制（图 1)。区域创新环境可划 分为软环境与硬环境, 其中前者包括市场环境、制度环境和文化环境, 而后者则包括基 础设施环境、金融环境和人力资源环境等。产业结构转型主要通过产业结构高度化与产 业结构合理化来体现，其中前者表现为从第一产业占优势向第二、三产业占优势方向顺 次演进, 从劳动密集型向资本密集型、技术密集型方向顺次演进, 由低附加值向高附加 值, 低加工度产业向高加工度产业方向顺次演进, 提升创新能力与劳动生产率, 而后者 主要表现在产业之间协调能力的加强与关联水平的提高 ${ }^{[27]}$ 。本文尝试分析上述不同角度 的创新环境与产业结构高度化、合理化之间的耦合关系机制，进而明确创新环境与产业 结构转型的空间耦合机理。

基础设施是区域各种创新要素集聚与扩散的重要载体，而基础设施环境优化有助于 加速人才、资金、技术等创新要素的集聚与扩散 ${ }^{[28]}$, 这不仅可以降低交易成本、运输成 本以及信息搜寻成本等, 而且有利于区域产业分工协调与技术外溢, 进而提升区域产业 结构高级化、合理化水平。另一方面, 区域产业结构转型对基础设施环境要求会进一步 提高，并在一定程度上促进对基础设施环境建设的投人，从而不断优化基础设施环境。

市场环境优化有助于规避盲目投资与过度生产，完善企业进人或退出机制，促进创 新资源有效流动与配置; 有助于及时获得市场需求信息, 促使市场竞争环境公平有效; 


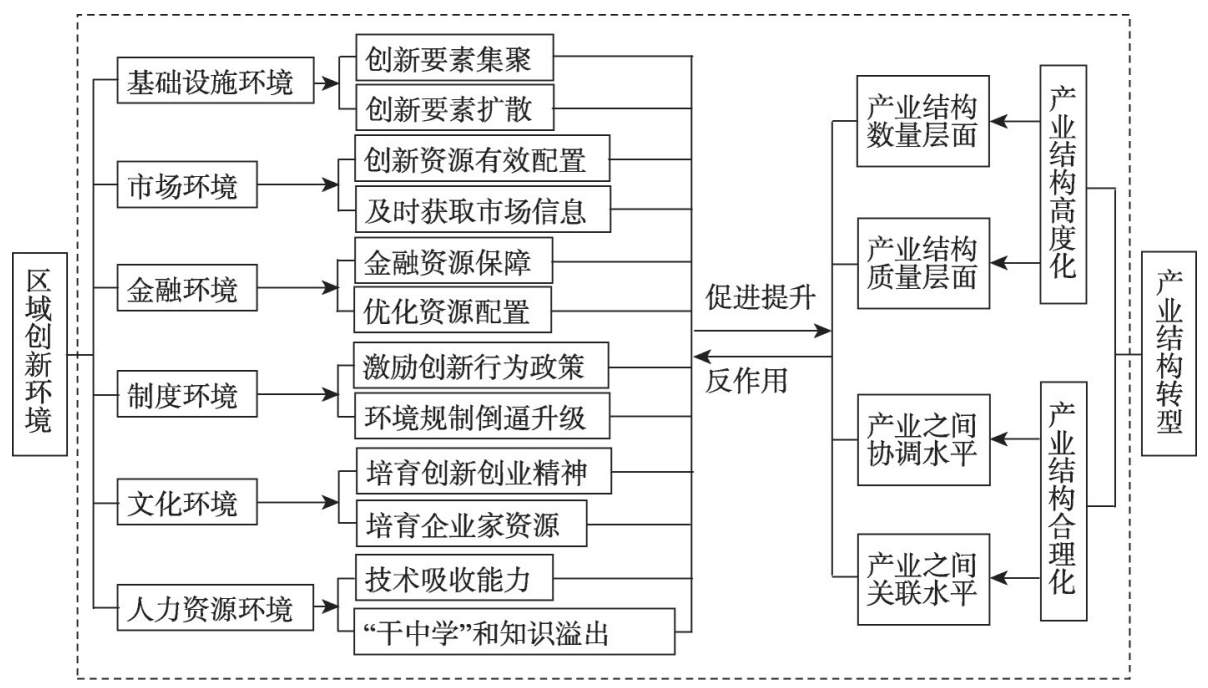

图 1 区域创新环境与产业结构转型空间耦合机理

Fig. 1 The coupling mechanism between regional innovative milieu and industrial structure transformation

有助于降低创新风险与固定成本，从而激励创新行为与提升劳动生产率 ${ }^{[28,29]}$, 提升产业结 构高级化、合理化水平。此外，产业结构转型有助于更加明确政府与市场的关系，为多元 化的市场主体搭建更加公平开放的平台, 使市场主体均可在平等的市场环境中参与竞争, 共享产业结构转型带来的红利, 进而提升市场环境的科学性、透明性、开放性和有序性。

产业结构转型需要大量的资金投人，而良好的金融环境能为区域创新主体，尤其是 创新型中小民营企业提供必要的资金支持、有效的风险管理以及更加多元化的融资渠 道。这有助于降低企业融资成本, 激励企业主动创新, 促进产融无缝对接与协同发展, 从而实现产融链条上各环节利益的合理分配 ${ }^{[30]}$, 进而提升产业结构高级化、合理化水 平。此外，区域产业结构转型可以有效保障金融体系功能的充分发挥，进一步带动金融 结构的发展，拓展金融发展空间，从而优化区域金融环境，进而促进产业结构转型与金 融环境优化的互促互进。

完善的制度环境可以弥补市场不健全，提升资源配置的有效性，是产业结构转型的 关键, 具体主要采取激励政策与环境规制手段促进产业结构转型。一方面通过建立有效 的知识产权保护、创新专项补贴等政策降低交易成本与创新成本, 激励创新主体主动创 新; 另一方面, 通过适度的环境规制手段抑制高污染、高耗能企业发展, 倒逼企业创新 升级, 促进产业结构向知识密集型、环境依存度低的产业结构调整 ${ }^{[3,132]}$, 促进资源优化配 置，进而提升产业结构高度化、合理化水平。此外，区域产业结构转型会对制度环境优化 提出更高、更新的要求，这有助于进一步健全相关政策法规，减少政府对企业经营的直接 干预或限制，加大对科技创新成果知识产权的保护力度，从而促进制度环境的不断优化。

区域文化环境反映区域内在精神、价值观、社会规范和惯例等，而良好的区域文化 环境能有助于培育企业家资源与创新创业精神等，促进创新主体间相互信赖，营造 “包 容失败” 的创新氛围, 从而降低创新不确定性, 激励主动创新行为 ${ }^{[10]}$; 有助于衍生主导 优势产业、新兴产业等，不断改造提质传统产业，进一步强化产业间关联度，进而提升 产业结构高度化与合理化水平。此外, 产业结构转型有助于在全社会营造尊才重才的社 会环境，培育鼓励创新、宽容失败的创新创业文化氛围，弘扬创新创业精神，从而进一 
步优化区域文化环境。

优质人力资源是科技创新的知识源泉和根本动力，是产业结构转型的重要基础。人 力资源环境优劣直接影响区域自主创新能力、技术（知识）吸收能力，以及 “干中学” 和知识外溢效果。优质人力资源环境应是一个 “人尽其才、才尽其用” 的环境 ${ }^{[4]}$, 它为高 素质人才开展创新活动提供良好的创新平台, 促进高素质人才的有效流动与配置, 加速

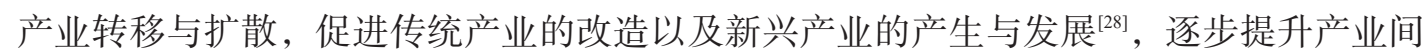
关联度，进而提升区域产业结构高度化与合理化水平。另一方面，产业结构转型则进一 步促进人力资源需求从物质生产部门流向非物质生产部门, 尤其反映在对高素质人力资 本的强烈需求上 ${ }^{[33]}$, 进而充分发挥人力资源的重要影响，逐渐完善区域就业结构，促进 人力资源环境的不断优化。

\section{2 研究方法与数据来源}

\section{1 研究方法}

\subsection{1 创新环境测度模型}

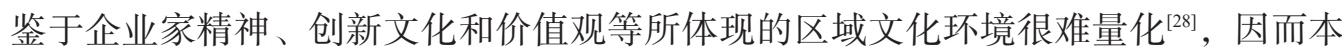
文构建的资源型城市创新环境评价指 标体系选择基础设施环境、市场环 境、金融环境、制度环境和人力资源 环境五个方面的 25 个指标（表 1 ）。 运用SPSS 软件对 2003 年、2016年的 资源型城市创新环境评价指标体系进 行降维处理, 其中主成分分析为处理 降维的常见方法之一。通过 2003 年、2016年的 KMO 检验表明其均适 合做因子分析，同时依据主成分特征 根（大于 1) 分别提取 6 个主成分, 其方差累计贡献率分别为 $93.16 \%$ 和 93.00\% , 然后根据其累计贡献率确 定主成分权重，最后据此测度综合 得分排名来评价资源型城市创新环 境水平。

\subsection{2 产业结构转型的度量指标}

（1）产业结构高级化 (UPG) 指数 产业结构高级化主要选择产业结 构高级化指数来表达, 其计算步骤如 下 $^{[34]}$ : 首先将一、二、三产业占 GDP 比例作为空间向量的一个分量，从而 构成一组三维向量 $X_{0}=\left(x_{1,0}, x_{2,0}, x_{3,0}\right)$ 。 在此基础上, 分别测度 $X_{0}$ 与产业由低层 次向高层次排列的向量 $X_{1}=(1,0,0)$ 、

\section{表 1 区域创新环境评价指标体系}

Table 1 The evaluation index system of regional innovative milieu

\begin{tabular}{|c|c|}
\hline 要素层 & 指标层 \\
\hline 基础设施环境 & $\begin{array}{l}\text { 每百人公共图书馆藏书量/(册/百人) } \\
\text { 每百人固定电话与手机数量/部 } \\
\text { 人均拥有铺装道路面积/(m²/人) } \\
\text { 邮电业总量/万元 } \\
\text { 客运量/万人 } \\
\text { 货运量/万 } \mathrm{t}\end{array}$ \\
\hline 人力资源环境 & $\begin{array}{l}\text { 普通高校在校教师人数/人 } \\
\text { 普通高校在校学生人数/人 } \\
\text { 普通高校数/所 } \\
\text { 科技活动人员数量/人 } \\
\text { 教育支出占 GDP 比例 } / \%\end{array}$ \\
\hline 金融环境 & $\begin{array}{l}\text { 金融机构贷款总额/亿元 } \\
\text { 金融机构存款总额/亿元 }\end{array}$ \\
\hline 市场环境 & $\begin{array}{l}\text { 在岗职工平均工资/元 } \\
\text { 人均居民可支配收人/元 } \\
\text { 地区生产总值/万元 } \\
\text { 出口总额占 GDP 比例 } / \%\end{array}$ \\
\hline 制度环境 & $\begin{array}{l}\text { R\&D 经费支出额/万元 } \\
\text { R\&D 经费支出占 GDP 比例 } / \% \\
\text { 研发机构数/个 } \\
\text { 科学技术支出占地区生产总值比例 } / \% \\
\text { 非国有经济职工人数/人 } \\
\text { 非国有经济职工人数占总职工人数比例 } / \% \\
\text { 非国有经济工业总产值/万元 } \\
\text { 非国有经济工业总产值占工业总产值比例 } / \%\end{array}$ \\
\hline
\end{tabular}


$X_{2}=(0,1,0) 、 X_{3}=(0,0,1)$ 的夹角 $\theta_{1} 、 \theta_{2} 、 \theta_{3}$ :

$$
\theta_{j}=\arccos \left(\frac{\sum_{i=1}^{3}\left(x_{i, j} \times x_{i, 0}\right)}{\left(\sum_{i=1}^{3} x_{i, j}^{2}\right)^{1 / 2} \times\left(\sum_{i=1}^{3} x_{i, 0}^{2}\right)^{1 / 2}}\right) \quad(j=1,2,3)
$$

那么, 产业结构高级化指数用 $U P G$ 表示, 该指数越大说明产业结构高级化水平越 高，具体计算公式如下:

$$
U P G=\sum_{k=1}^{3} \sum_{j=1}^{k} \theta_{i}
$$

（2）产业结构合理化指数

产业结构合理化反映产业之间的协调程度，以及资源有效利用的程度，而泰尔熵指 数能够有效地评价产业结构合理化水平 ${ }^{[35]}$ ，其计算公式如下:

$$
U=1-T_{l}=1-\sum_{i=1}^{3}\left(\frac{Y_{i}}{Y} \ln \frac{Y_{i} / Y}{L_{i} / L}\right)
$$

式中： $U$ 为产业结构合理化指数; $T_{l}$ 为泰尔熵指数; $Y_{i}$ 和 $L_{i}$ 分别表示第 $i$ 产业从业人员和 产值; $Y$ 和 $L$ 分别表示三次产业从业人员数量及产值。 $U$ 越大，说明产业结构越合理。

\subsection{3 耦合协调发展度模型}

耦合指两个或多个系统或运动方式经各种相互作用而彼此影响的现象，而耦合度可 有效测算系统之间的协调程度 ${ }^{[36,37]}$, 本文尝试从上述产业结构转型的两个维度探讨创新环 境与产业结构转型之间的动态耦合机制。需要强调的是：因创新环境综合得分仅表示相 对优势且可能为负数，直接影响耦合度模型的测度，故首先借鉴郭艳军等 ${ }^{[38}$ 的处理方 法, 通过线性平移变换使创新环境综合得分归结为结构相对数，而这并不影响作用结 果，然后采用归一化方法对其进行标准化处理。具体涉及的主要计量模型公式如下:

$$
\begin{gathered}
C=2\left\{\left(u_{1} \times u_{2}\right) /\left[\left(u_{1}+u_{2}\right)\left(u_{1}+u_{2}\right)\right]\right\}^{1 / 2} \\
D=(C \times T)^{1 / 2}, T=a u_{1}+b u_{2} \\
E=u_{1}^{\prime} / u_{2}^{\prime}
\end{gathered}
$$

式中: $u_{1}$ 和 $u_{2}$ 分别表示创新环境与产业结构高级化指数（或合理化指数）； $u_{1}^{\prime}$ 和 $u_{2}^{\prime}$ 表示 数据标准化归一化处理后的创新环境与产业结构高级化指数（或合理化指数）; $C$ 为耦合 度指数，该值越大说明两者作用越强，当值为 1 时，表示两者达到良好的共振耦合。参 考刘耀涁等 ${ }^{[39}$ 将 $C$ 值以 $0.3 、 0.5 、 0.8$ 为分界点, 将其分成低度、较低、较高和高度耦合 4 种类型。 $D$ 为协调度指数 $(0 \leqslant D \leqslant 1), D$ 值越大说明双方发展越协调, 反之则越失调; $T$ 为双方综合调和指数; $a 、 b$ 为待定系数，一般均取 $0.5^{[40]}$ 。参考已有研究，以 $0.3 、 0.4$ 、 $0.5 、 0.7$ 和 0.8 为分界点, 将其分成严重失调、中度失调、轻度失调、勉强协调、中度协 调和高度协调。 $E$ 为相对发展度指数，在参考刘浩等 ${ }^{[4]}$ 对相对发展度指数划分标准的基础 上, 将创新环境与产业结构转型的相对发展度分为三种类型：当 $E \geqslant 1.2$ 时为创新环境超 前型，当 $0.8<E<1.2$ 时为同步发展型，而当 $E \leqslant 0.8$ 时为创新环境滞后型。

\section{2 数据来源}

鉴于《全国资源型城市可持续发展规划（2013-2020年）》将山西省除太原市外的其 他 10 个地级市均人列全国资源型城市，加之考虑到吕梁市于 2003 年才获准撤地设市，因 此，本文以山西省 10 个资源型城市为对象，选择 2003 年、2016年两个时间断点，所涉 
及的数据主要源于 2004-2017年《山西省统计年鉴》与《中国城市统计年鉴》。

\section{3 结果分析}

\section{1 创新环境与产业结构转型水平评价}

\section{1 .1 资源型城市创新环境综合评价}

不同等级的创新环境质量随着时间的推移均发生不同程度的波动，其中原创新环境 质量较优城市出现骤降, 中等水平城市则稳步提升, 而最低水平城市虽略有波动, 但创 新环境质量始终处于全省末位的态势并未改变（表2）。具体来说，2003年城市创新环境 水平可划分为三类, 其中处于全省第一梯队的是大同和临汾, 其次是长治、运城、晋中 和晋城, 而其他 4 个城市则较差。2003 年创新环境得分排名较高的大同于 2016 年出现骤 降（由第 1 名降至第 6 名），主要是因为大同尽管煤炭资源丰富，工业基础较好，但目前 面临的产业结构失衡，污染物总量控制任务艰巨，节能降耗工作艰巨，技术创新投人不 足, 海外市场不断收缩等问题愈加严峻, 这从创新环境部分关键指标变化可以充分说 明。相比 2003 年，2016年的大同研发机构数、科技人员数量、教育支出占 GDP 比例和 科学技术支出占 GDP 比例、出口额占 GDP 比例等均大幅下降，下降率分别为 $44.44 \%$ 、 $39.11 \%$ 、100.00\%、97.51\% 和 $96.21 \%$ 。与大同基本相似，临汾也正是由于这些创新基础 环境关键指标迅速下降，才使其创新环境相对优势迅速下降（由第 2 名降至第 5 名）。相 比临汾、大同，原处于中等创新环境水平的长治、运城、晋中和晋城，近年来加快创新 环境建设步伐，将全力营造良好的 “营商环境” 作为地方政府近年来推动经济转型升级 工作的重中之重, 并已取得丰硕的成果。以晋中为例, 除反映科技教育投人比例以及海 外市场等少数指标有所下降外, 其大部分指标均大幅增长, 如 2016 年反映创新环境的社 会发展指标：每百人公共图书馆藏书、邮电业总量、每百人固定电话与手机数量、在岗 职工平均工资、人均居民可支配收人、GDP 分别比 2003 年增长 $100 \%$ 、 $112 \%$ 、171\%、 $467 \%$ 、184\% 和 436\%，从而使 2016 年的晋中创新环境优化成效显著（由第 5 名升至第 2 名)。此外，创新环境较差的城市因受资金、技术、人才和政策等因素制约，其创新环境 优化成效较小，包括阳泉、朔州、吕 梁和忻州，其创新环境水平始终为全 省最低，其主要原因是它们尽管随着 时间的推移，其人力资源环境、基础 设施环境、制度环境等均得到了不同 程度的改善, 但与省内其他城市比, 诸多指标基数较小，即原创新环境的 基础较差，从而导致这些城市创新环 境并没有通过自身的努力而改变其在 全省依然处于最低水平的态势。

\subsection{2 产业结构转型的空间演变特征}

2003-2016年，山西资源型城市 产业结构高级化指数均呈增大趋势 (图2), 转型水平明显提升。这主要

\section{表 2 山西资源型城市创新环境综合排名}

Table 2 The comprehensive ranking of innovative milieu about resource-based cities in Shanxi province

\begin{tabular}{ccccccc}
\hline \multirow{2}{*}{ 城市 } & \multicolumn{2}{c}{2003 年 } & & \multicolumn{2}{c}{2016 年 } \\
\cline { 2 - 3 } \cline { 5 - 6 } \cline { 5 - 6 } 大同市 & 0.801 & 1 & & 0.098 & 6 \\
临汾市市 & 0.531 & 2 & & 0.114 & 5 \\
长治分 & 排名 & & 综合得分 & 排名 \\
运城市 & 0.365 & 3 & & 0.565 & 1 \\
晋中市 & 0.110 & 4 & & 0.393 & 3 \\
晋城市 & 0.086 & 5 & & 0.425 & 2 \\
阳泉市 & 0.061 & 6 & & 0.388 & 4 \\
忻州市 & -0.201 & 7 & & -0.476 & 8 \\
吕梁市 & -0.475 & 8 & & -0.872 & 10 \\
䍭州市 & -0.610 & 9 & & 0.023 & 7 \\
\hline
\end{tabular}



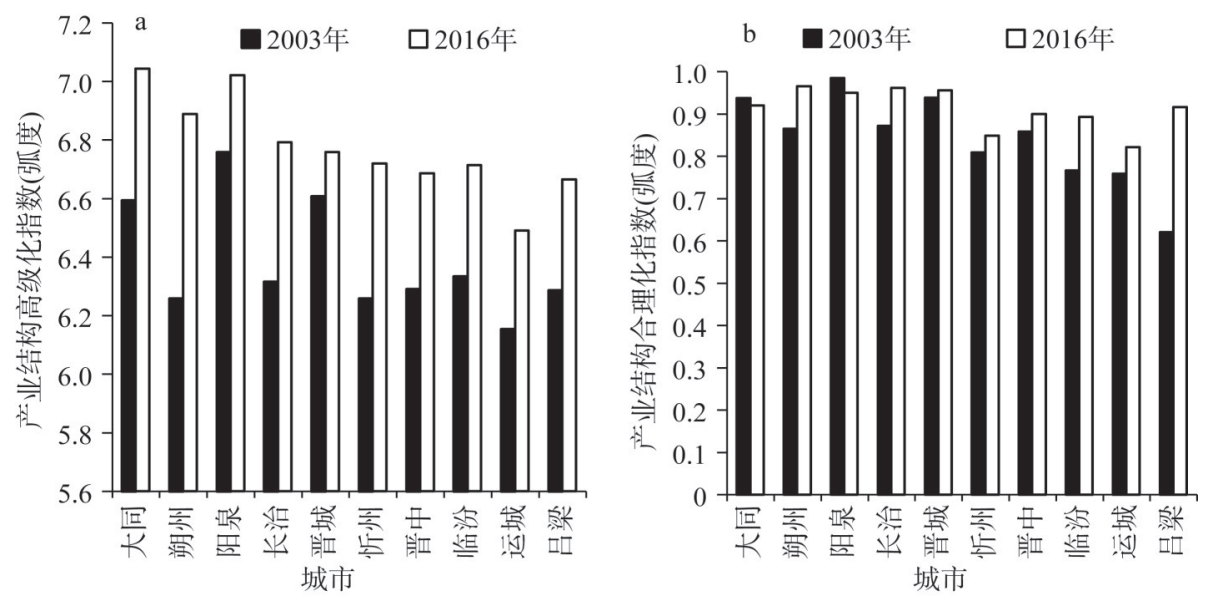

图 2 山西资源型城市产业结构高级化指数与产业结构合理化指数变化

Fig. 2 The changes of industrial structure advancement index and industrial structure rationalization index about the resource-based cities in Shanxi province

是因为各城市近年来大力实施创新驱动与产业转型升级的战略，如 “六大发展” “三个突 破”、煤与非煤 “两篇大文章” 等，从而使其产业结构逐渐高级化，这与它们产业结构发 展阶段变化趋势也基本一致：2003 年城市产业结构由 “二、三、一”阶段逐渐转变为 2016年的 “三、二、一” 和 “二、三、一” 并存格局，其中第一产业、第二产业的产值 比例在该时段内总体处于下降趋势，而第三产业逐年上升。可见，随着时间的推移，各 城市产业结构逐渐由较低层次向较高层次转变，但依然存在 $40 \%$ 的城市产业结构尚未进 人产业结构演进的高级阶段，其经济发展依然具有很强的工业化过程特征，且低于同年 全国产业结构的平均水平。此外，2003年，大同和阳泉的产业结构高级化指数较高，总 体超过 6.60 , 并随着时间的推移而高速增长。这主要是因为它们属于山西最典型的煤炭 资源型城市，受煤炭资源刚性约束及生态环境压力较大，因而其地方政府或相关企业近 年来多措并举, 着力促进城市产业结构转型, 包括培育战略性新兴产业, 加快发展非煤 工业、文化旅游业和现代服务业等，逐步推进资源依赖型城市向创新驱动型城市转变。

在产业结构合理化方面，各城市产业结构合理化指数较高，且变化复杂；除大同、 阳泉略有下降外，其他城市均出现不同程度的上升，这说明随着时间的推移，各城市通 过坚定不移地去产能, 加快绿色转型, 大力实施创新驱动战略, 逐步推进不同产业间协 调发展以及资源的有效利用，进而使得绝大部分城市的产业结构合理化态势趋好。此 外，大同与阳泉产业结构合理化指数尽管随着时间的推移而略有下降，但其在该时段内 始终处于较高水平，而处于最低水平的产业结构合理化指数则骤升，最为突出的是吕 梁，其产业结构合理化指数由 2003 年的 0.621 上升至 2016 年的 0.916 , 增长率达 $47.50 \%$, 是增速位居第二的临汾的 2.90 倍。这说明以大同、阳泉为代表的高水平产业结构合理化 城市, 由于近年来始终着力推进煤炭产业 “六型转变”，加快提升煤炭资源集中开发和综 合循环利用能力, 强化产业错位发展, 着力促进城市的产业合理分工与良性互动, 进而 使其产业结构合理化指数始终处于较高水平; 吕梁属于典型的资源型欠发达城市，自 2003 年获准撤地设市以来长期存在产业结构单一、“一煤独大”、产业间协调度不高、循 环经济发展不足等现象，其产业结构合理化指数于 2003 年为全省最低，而随着时间的推 
移, 吕梁近年来将加快发展现代服务业作为促进产业结构转型的重大战略举措, 并实施 煤、焦、铁、电和化工等传统优势产业进行园区集聚、项目推动、循环经济牵动和扶持 自主创新等战略举措，并均已取得显著成效，从而使其产业结构合理化水平近年来得到 显著提升。

\section{2 创新环境与产业结构转型的空间耦合特征}

\subsection{1 创新环境与产业结构转型耦合协调度分析}

运用耦合协调度模型测度创新环境与产业结构转型两个维度之间的耦合度与协调 度，结果表明：2003年与 2016 年，创新环境与产业结构高级化、合理化之间的空间耦合 变化图完全相同（图3), 而且 $60 \%$ 城市耦合度指数呈下降趋势。2003年, 各城市耦合度 指数均超过 0.80 , 其中除了朔州与吕梁低于 0.90 以外, 其他城市均接近于 1 , 这说明所有 城市创新环境与产业结构转型均呈高度耦合, 两者相互作用强度较高, 基本达到良好的 共振耦合。与之相比, 2016年, 忻州耦合度指数出现下降, 并转变为较高耦合区, 而其 他城市耦合度指数继续保持高值稳定状态，依然为高度耦合区，这说明随着时间的推 移, 各城市创新环境与产业结构转型之间的相互作用强度始终较高。此外, 忻州耦合度 指数的急剧下降主要是由于该城市创新环境始终处于全省劣势地位, 且该态势日益凸显, 无法较好地满足产业结构转型的要求, 对产业结构转型促进作用不强, 贡献度不高所致。

与之相比, 城市创新环境与产业结构转型两个维度的协调度空间格局也完全一致, 其协调度指数均较低。除了吕梁、阳泉分别由 2003 年的严重失调区、中度失调区转变为 2016年的中度失调区、严重失调区以外, 其他城市协调度指数格局未发生明显变化, 整 体呈现 “南北中度失调、中间严重失调” 的格局。可见，山西 “南北” 区域属于高度耦 合一中度失调区，而 “中间” 区域则属于高度耦合一严重失调区，这说明城市创新环境 与产业结构转型两个维度之间存在较为严重的偏离现象, 并未在结构与功能上实现理想
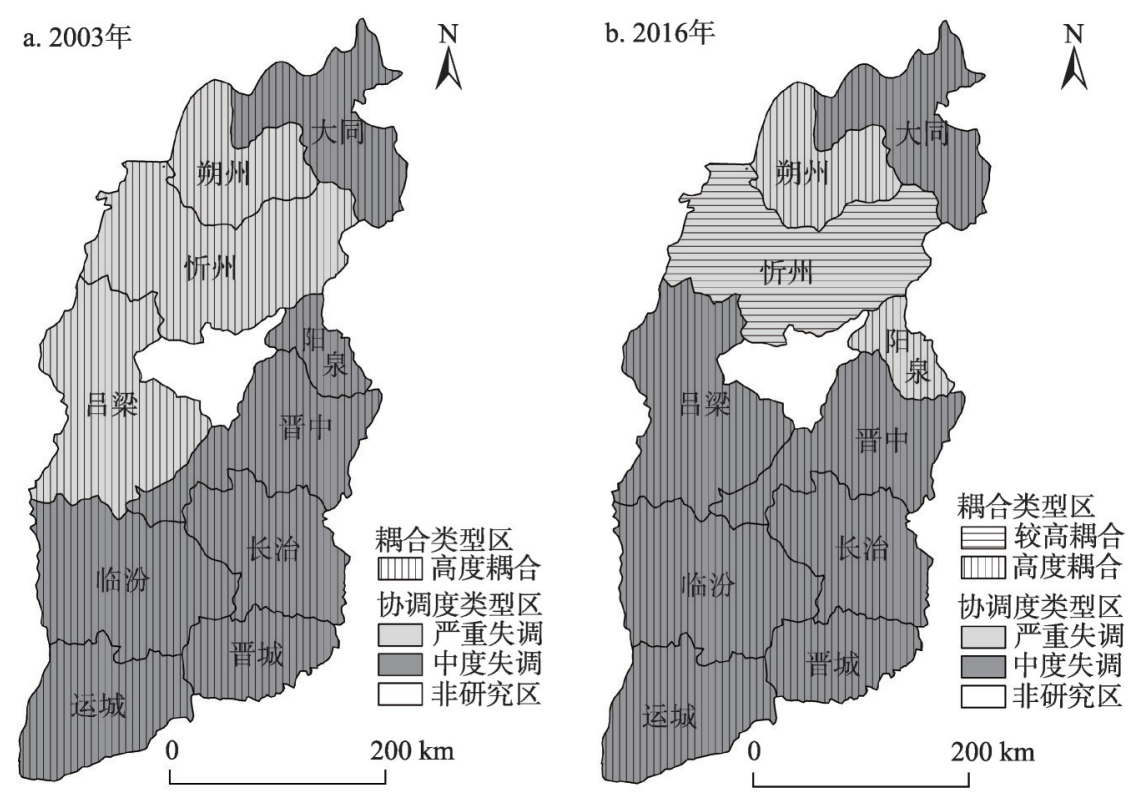

图 3 山西资源型城市创新环境与产业结构高级化（或合理化）耦合协调度空间格局演变

Fig. 3 The spatial pattern of coupling coordination degree between innovative milieu and industrial structure advancement (or industrial structure rationalization) about the resource-based cities in Shanxi province 
状态下的良性互动，其主要原因依然是 “中间” 区域的创新环境水平近年来尽管得到不 同程度的提升, 但其发展相对滞后, 产业结构转型在快速推进过程中缺乏良好的创新环 境支撑, 亟待增强创新环境对产业结构转型的创新驱动作用。不仅如此, 这也体现了作为 太原市位于山西省会城市与重要核心城市, 其创新环境水平较高, 但其对毗邻的忻州、 阳泉等城市的带动辐射作用较弱, 因而亟需增强太原市的综合实力与辐射力, 进一步提 升其中心城市能级，进而实现太原与其周边城市创新环境与产业结构转型的互促互进。

3.2.2 创新环境与产业结构转型相对发展度格局

为进一步刻画资源型城市创新环境与产业结构转型两个维度之间的同步发展程度, 引人相对发展度模型进行分析（图 4、图 5)。结果表明：各城市创新环境与产业结构高 级化、合理化之间的相对发展度格局基本一致，总体均呈现 “南北” 区域属于创新环境 超前型或同步发展型，而 “中间” 区域主要为创新环境滞后型; 随着时间的推移，60\% 的城市创新环境与产业结构转型的相对发展度指数呈上升趋势, 但其相对发展度格局并 没有因此发生显著变化, 而且绝大部分城市创新环境水平依然低于产业结构转型水平或 彼此相当, 这说明尽管大部分城市的创新环境优化速度明显快于产业结构转型速度, 但创 新环境依然未形成显著优势, 其对产业结构转型两个维度的促进作用未能充分发挥, 亟 待进一步增强。

（1）创新环境超前型。对产业结构高级化来说，2003年此类城市包括临汾、大同和 长治, 而 2016 年仅包括晋中、长治、晋城和运城, 主要因为这 4 个城市近年来的创新环 境质量优化成效显著, 或始终处于高水平, 而产业结构高级化水平尽管实现不同程度的 提升, 但创新环境对产业结构转型的促进作用尚未充分发挥。与之相比, 随着时间的推 移，大同和临汾的相对发展度出现大幅度下降，其下降率分别为 $42.08 \%$ 和 $29.64 \%$, 并从 创新环境超前型向同步发展型转变，这是因为近年来大同、临汾创新环境质量在全省的 优势骤降，而产业结构高级化指数迅速上升所致。对产业结构合理化来说，2003年的创
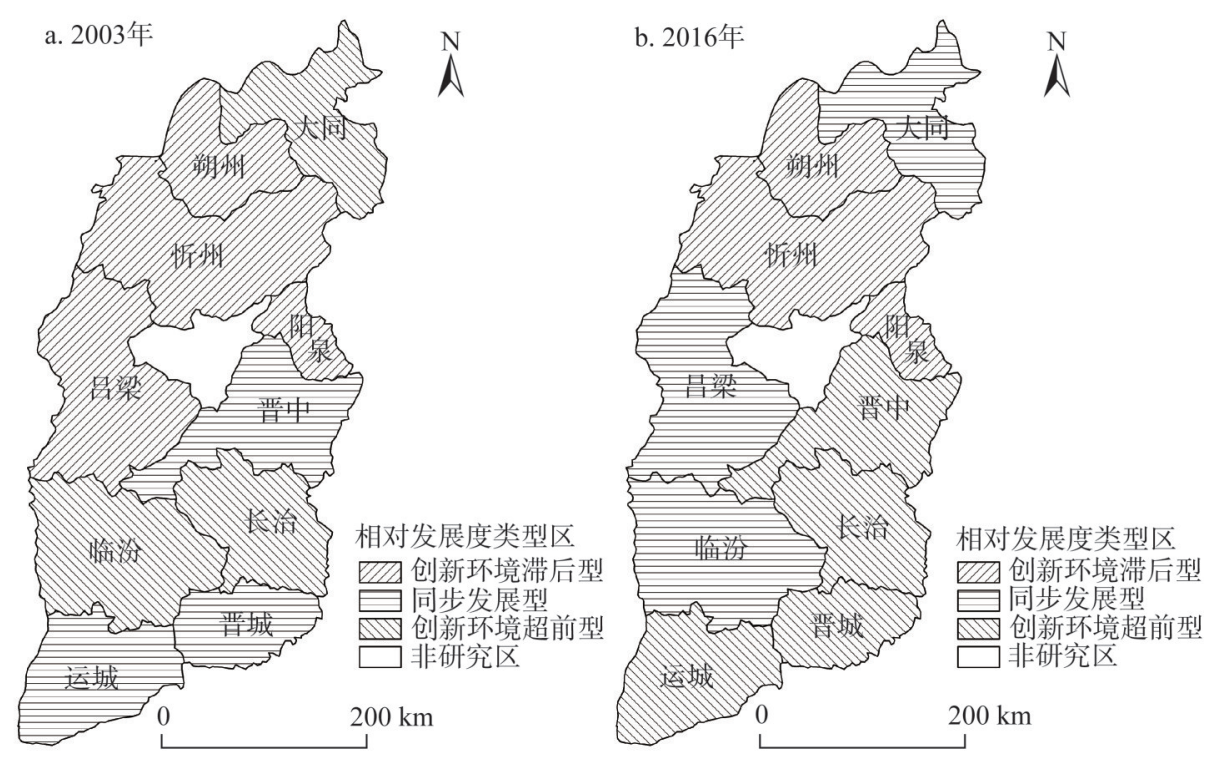

图 4 山西资源型城市创新环境与产业结构高级化相对发展度空间差异变化

Fig. 4 The changes of spatial difference of relative rate between innovative milieu and industrial structure advancement about the resource-based cities in Shanxi province 

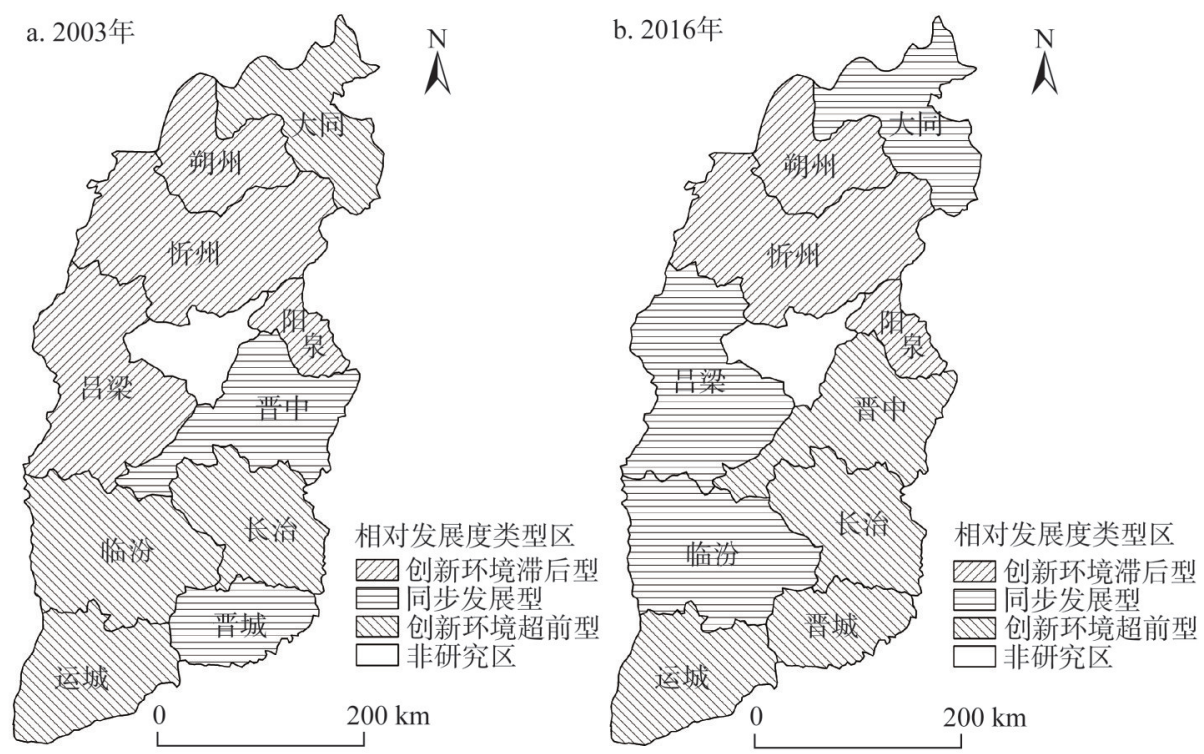

图 5 山西资源型城市创新环境与产业结构合理化相对发展度空间差异变化

Fig. 5 The changes of spatial difference of relative rate between innovative milieu and industrial structure rationalization about the resource-based cities in Shanxi province

新环境超前型城市除了上述临汾、大同、长治外，还包括运城，2016年则包括长治、运 城、晋中和晋城, 而临汾、大同则由创新环境超前型转变为同步发展型, 这依然与临 汾、大同近年来的创新环境骤降及产业结构合理化水平出现上升或趋于稳定密切相关。

（2）创新环境与产业结构转型同步型。对产业结构高级化来说，2003 年此类城市主 要为晋中、晋城与运城 3 个城市, 2016年则包括临汾、大同和吕梁。而对产业结构合理 化来说，2003 年该类城市仅晋中与晋城，而2016年同样也转变为临汾、大同和吕梁。其 中吕梁创新环境质量与产业结构转型水平均较低，在全省并不具备优势，而随着时间的 推移, 该城市创新环境优化与产业结构转型的步伐逐渐加快, 其创新环境、产业结构转 型的水平以及在全省的优势地位均不断提升, 尤其创新环境优化成效最为显著, 从而使 该城市的相对发展度骤升, 并从创新环境滞后型转变为同步发展型。尽管如此, 吕梁创 新环境与产业结构转型水平在全省依然不具优势，仍旧面临诸多困难与挑战亟待解决。

（3）创新环境滞后型。2003年，此类型城市包括朔州、忻州、吕梁和阳泉，而 2016 年除吕梁由创新环境滞后型转变为同步发展型外，还包括朔州、忻州和阳泉。其中朔州 相对发展度指数随着时间的推移略有增长, 其创新环境原处于全省最低水平, 产业结构 转型水平也较低, 而近年来该城市充分意识到资源型城市创新环境对产业结构转型的重 要性, 采取针对性的措施加快推进创新环境建设优化, 而其目前的创新环境水平依然处 于最低层次, 对产业结构转型的支撑作用有所增强但依然不强。阳泉和忻州相对发展度 较低且呈逐年下降, 尤以前者降幅更大, 其中前者相对发展度是后者的倍数由 2003 年的 1.5 倍增至 2016 年的 5 倍左右, 这主要是因为它们创新环境发展基础均较弱, 而且近年来 在全省的弱势地位逐渐加剧, 尤以忻州更为显著, 而在产业结构转型水平方面, 阳泉明 显优于忻州且前者趋于稳定, 后者增幅明显, 从而导致它们创新环境水平始终无法满足 产业结构转型发展的要求, 同时产业结构转型发展对创新环境优化的促进作用依然有 
限，进而致使它们属于创新环境滞后型的现状并未随着时间的推移而发生变化。

\section{4 结论与讨论}

\section{1 结论}

运用 ArcGIS 的空间分析技术与多种数理统计模型，对 2003年、2016年山西资源型 城市的创新环境与产业结构转型空间耦合格局演变进行分析, 主要研究结论如下:

(1) 不同优势的城市创新环境质量随着时间的推移均发生不同程度的波动，其中创 新环境综合得分排名位居前列的城市, 其创新环境质量优势出现骤降, 处于中等水平的 创新环境质量优势稳步提升，而处于最低水平城市的创新环境优势未实现突破性的提升。

（2）所有城市产业结构转型高级化指数均呈增大趋势，而产业结构合理化指数较高 且变化相对复杂, 与冯江茹等 ${ }^{[2]}$ 的研究结论基本一致; 除大同、阳泉产业结构合理化指 数略有下降以外, 其他城市均出现不同程度地提高, 尤其处于最低水平的吕梁升幅最大。

（3）原创新环境与产业结构转型的耦合度指数较高，均为高度耦合区，且大部分城 市随着时间的推移均出现不同程度的下降，其中忻州由高度耦合区转变为较高耦合区; 与之相比, 创新环境与产业结构转型的协调发展度较低, 整体呈 “南北中度失调、中间 严重失调”的格局，且此格局并未随着时间的推移而发生明显变化。

（4）大部分城市的相对发展度呈上升趋势，山西 “南北” 区域属于创新环境超前型 或同步发展型，而 “中间” 区域主要被创新环境滞后型所覆盖，且该格局并未随着时间 的推移而发生显著变化。

（5）由于数据获取存在难度，区域创新环境指标体系构建还有待完善; 研究时间断 点仅 2003 年与 2016年, 缺乏对其更多时间断面的空间耦合特征分析等, 而这些也是未来 研究有待进一步深化的重要内容。

\section{2 讨论}

由于不同类型的资源型城市创新环境与产业结构转型的耦合协同发展面临的重点与 难点有所不同，因而尝试立足各资源型城市的实际，提出相应的对策建议：

（1）产业结构转型发展依然是重中之重。从上述相对发展度指数测度结果可知，与 创新环境相比, 大部分城市的产业结构转型水平较滞后, 如 2016年, 创新环境与产业结 构高级化、合理化指数之间的相对发展度大于 1 的城市数量均占所有城市的 $70 \%$, 加之 其中的大同、临汾和吕梁此时创新环境质量并不高，仅处于全省中下水平，可见，导致 山西资源型城市创新环境与产业结构转型耦合协调度不高的根本原因是产业结构转型水 平过低。基于此，此类城市应当在继续加快创新环境优化步伐的同时，重点围绕其境内 煤炭、铝、铁等特色矿产资源优势，改造提质电力、化工、钢铁、铝加工等传统优势产 业, 加快推进产业链条延伸, 实现产品升级换代; 充分利用其境内现有的产业基础与特 色资源优势, 如临汾的精密铸造、锻造等产业基础以及煤层气、风力、太阳能等绿色资 源, 长治与晋城的中药材资源, 吕梁的国家数据产业基地与云计算中心等优势, 通过加 强与国内外知名院校和科研院所建立合作，做大做强先进装备制造、生物医药、现代化 工、新材料、新能源、电子信息等战略性新兴产业, 实现产业集聚集群集约发展; 重点 以 “黄河、长城、太行” 三大旅游板块为主要支撑, 各城市依托当地世界级文化旅游资 源与品牌, 推进文旅、农旅、体旅、工旅的深度融合, 全力打造文化旅游战略性支柱产 业, 进而促进产业结构转型发展。 
（2）创新环境亟待持续优化，主要以朔州、忻州和阳泉等城市为代表，其创新环境 质量始终处于全省最低水平的态势并未随着时间的推移而明显改变。在继续加快产业结 构转型步伐的基础上，充分借助毗邻太原的有利区位，如忻州与阳泉，应积极融人太原 都市圈，加快城际重大交通基础设施建设，尤其是与太原之间的高铁或高等级公路的规 划与建设，加快推进基础设施内联外通，以及人力资源、资金、技术、物流等生产要素 的快速流动与集聚，有效降低与太原市之间的时间成本、物流成本等，促进其创新环境 优化与产业结构转型; 全力推进 “百千万” 人才工程和 “百校千人” 计划, 积极引导企 业和高等院校、科研院所、企业家和教授共建院士专家工作站、技术研发中心、科技服 务站；地方政府应设立专项资金鼓励企业科技创新，激励企业主动与国内外知名高校或 科研院所进行深度合作，并依托重大科研项目、重点实验室等人才培养载体，着力培养 高层次创新型科技人才与激活本地人才; 全力打造 “六最” 营商环境, 建设科技创新风 险投资基金和中小微企业双创基地，从而为产业结构高质量转型发展营造良好的创新创 业环境。

（3）创新跨区域协同发展机制，包括山西省内城市之间的跨区域协同发展机制，以 及山西跨省域协同发展机制。一方面，突破原有的地方本位思想，省内各城市要立足实 际, 扬长避短, 充分发挥当地优势, 有选择地重点发展具有比较优势的行业, 有助于促 进产业结构错位发展与创新环境优化，努力消除城市普遍存在的 “行政区经济” 现象; 另一方面, 还应进一步加大改革开放力度, 加强山西与外部重要经济发展引擎（如京津 冀）之间建立和谐顺畅的跨区域行政管理协作机制，促进彼此间生产要素的跨区域合理 化流动与行为主体之间的合作，保障区域经济协同发展，进而促进山西资源型城市产业 结构转型与创新环境的并进协同发展。

\section{参考文献(References):}

[1] 申玉铭, 杨彬彬, 张云. 资源型城市的生态环境问题与综合整治: 以济宁市为例. 地理研究, 2006, 25(3): 430-438. [SHEN Y M, YANG B B, ZHANG Y. Study on the eco-environmental problems and its countermeasures in the sustainable development of resources-based cities: A case study of Jining city. Geographical Research, 2006, 25(3): 430-438.]

[2] 苗长虹, 胡志强, 耿风娟, 等. 中国资源型城市经济演化特征与影响因素: 路径依赖、脆弱性和路径创造的作用. 地理 研究, 2018, 37(7): 1268-1281. [MIAO C H, HU Z Q, GENG F J, et al. Characteristics of economic evolution and the influencing factors of resource-dependent cities in China: The role of path dependence, vulnerability and path creation. Geographical Research, 2018, 37(7): 1268-1281.]

[3] 余建辉, 李佳洺, 张文忠. 中国资源型城市识别与综合类型划分. 地理学报, 2018, 73(4): 677-687. [YU J H, LI J M, ZHANG W Z. Identification and classification of resource-based cities in China. Acta Geographica Sinica, 2018, 73(4): 677-687.]

[4] 张文忠, 李业锦. 区域创新环境与企业发展研究. 软科学, 2003, 17(6): 25-28. [ZHANG W Z, LI Y J. A study on regional innovative milieu and enterprise development. Soft Science, 2003, 17(6): 25-28.]

[5] 王伟, 孙雷. 区域创新系统与产业转型耦合协调度分析: 以铜陵市为例. 地理科学, 2016, 36(2): 204-212. [WANG W, SUN L. Coupled analysis regional innovation system and resource city industrial transformation: A case study of Tongling city. Scientia Geographica Sinica, 2016, 36(2): 204-212.]

[6] 张文忠, 王岱, 余建辉. 资源型城市接续替代产业发展路径与模式研究. 中国科学院院刊, 2011, 26(2): 134-141. [ZHANG W Z, WANG D, YU J H. Study on the development path and pattern of substituted industry in resource-based cities. Bulletin of Chinese Academy of Sciences, 2011, 26(2): 134-141.]

[7] AYDALOT P. Milieux Innovation En Europe. Pairs: Gremi, 1986.

[8] 朱建新, 朱祎宏, 鲁若愚. 创新环境的要素构成及其影响机理. 中国科技论坛, 2016, (3): 119-125. [ZHU J X, ZHU Y H, LU R Y. Hierarchical structure of the innovation environment and its impact mechanism. Forum on Science and Technology in China, 2016, (3): 119-125.] 
[9] 胡太山, 解鸿年, 林建元. 高科技区域创新环境构成与发展再思考. 城市规划学刊, 2003, (3): 74-80. [HU T S, XIE H $\mathrm{N}$, LIN J Y. The composition and rethinking the development of innovative milieu in high-tech area. Urban Planning Forum, 2003, (3): 74-80.]

[10] 翁媛媛, 高汝喜. 科技创新环境的评价指标体系研究: 基于上海市创新环境的因子分析. 中国科技论坛, 2009, (2): 31-35. [WENG Y Y, GAO R X. Research on the evaluation index system of scientific and technological innovative milieu: Based on factor analysis of innovative milieu in Shanghai. Forum on Science and Technology in China, 2009, (2): 31-35.]

[11] 党文娟, 张宗益, 康继军. 创新环境对促进我国区域创新能力的影响. 中国软科学, 2008, (3): 52-57. [DANG W J, ZHANG Z Y, KANG J J. The impact of regional innovation environment on the regional innovation capability. China Soft Science, 2008, (3): 52-57.]

[12] 千庆兰, 陈颖彪, 董晓敏. 中小企业技术创新行为与创新环境的实证研究: 基于广东省 785 家中小企业的问卷调查. 地理科学, 2008, 28(4): 488-495. [QIAN Q L, CHEN Y B, DONG X M. Technology innovation within small and middle enterprises and regional environment. Scientia Geographica Sinica, 2008, 28(4): 488-495.]

[13] 薛捷. 区域创新环境对科技型小微企业创新的影响: 基于双元学习的中介作用. 科学学研究, 2015, 33(5): 782-791. [XUE J. Research on the effect of regional innovation environment on technological small and microenterprises based on the mediation effect of exploration and exploitation learning. Studies in Science of Science, 2015, 33(5): 782-791.]

[14] 甄美荣, 杨晶照. 区域创新环境对区域内企业群落发展的影响机制研究. 科技进步与对策, 2012, 29(7): 42-46. [ZHEN M R, YANG J Z. Research on the influence mechanism of regional innovative milieu on the development of regional enterprise community. Science \& Technology Progress and Policy, 2012, 29(7): 42-46.]

[15] 吴玉鸣. 大学知识创新与区域创新环境的空间变系数计量分析. 科研管理, 2010, 31(5): 116-123. [WU Y M. A spatially varying-coefficient econometric analysis on university knowledge innovation capability and regional innovation milieu in China. Science Research Management, 2010, 31(5): 116-123.]

[16] 谢远涛, 李虹, 邹庆. 我国资源型城市创新指数研究: 以 116 个地级城市为例. 北京大学学报: 哲学社会科学版, 2017, 54(5): 146-158. [XIE Y T, LI H, ZOU Q. A study on the innovation index of resource-based cities in China: Taking 116 cities at the prefecture level for example. Journal of Peking University: Philosophy and Social Sciences, 2017, 54 (5): 146-158.]

[17] 王缉慈, 王可. 区域创新环境和企业根植性: 兼论我国高新技术企业开发区的发展. 地理研究, 1999, 18(4): 357362. [WANG J C, WANG K. Regional innovative milieu and local embeddedness. Geographical Research, 1999, 18(4): 357-362.]

[18] 马勇, 杜德斌, 周天瑜, 等. 地方创新环境对外资研发活动的影响分析: 深厦角青连五市的比较. 科学学与科学技术 管理, 2009, 30(5): 61-67. [MA Y, DU D B, ZHOU T Y, et al. An analysis on regional innovative milieu affecting foreign R \& D investment activity-the comparative study of five cities. Science of Science and Management of S. \& T., 2009, 30 (5): 61-67.]

[19] HALSETH G, SULLIVAN L, RYSER L. Service provision as part of resource town transition planning: A case from Northern BC. NRE/CRRF Conference, 2002.

[20] 刘云刚. 大庆市资源型产业结构转型对策研究. 经济地理, 2000, 20(5): 26-29. [LIU Y G. Studies on the adjustment of the industrial structure of resource type cities in the northeast area-Daqing as an example. Economic Geography, 2000, 20(5): 26-29.]

[21] 安树伟, 魏后凯. 东北资源型城市的产业结构转型. 经济管理, 2006, 26(3): 6-9. [AN S W, WEI H K. Study on industrial structure transformation of the resource-based cities in the Northeast China. Economic Management, 2006, 26(3): 6-9.]

[22] 庞娟. 资源枯竭型城市产业转型的风险规避与产业创新. 城市问题, 2006, (4): 69-72. [PANG J. The risk aversion and industrial innovation of industrial transformation about resources-exhausted cities. Urban Problems, 2006, (4): 69-72.]

[23] 邱成利. 创新环境及其对新产业成长的作用机制. 数量经济技术经济研究, 2002, 19(4): 5-7. [QIU C L. Innovative milieu and its mechanism on new industry growth. The Journal of Quantitative \& Technical Economics, 2002, 19(4): 5-7.]

[24] 叶丹, 黄庆华. 区域创新环境对高技术产业创新效率的影响研究: 基于 DEA-Malmquist 方法. 宏观经济研究, 2017, (8): 132-140. [YE D, HUANG Q H. Study on the influence of regional innovative milieu on innovation efficiency in high-tech industries. Macroeconomics, 2017, (8): 132-140.]

[25] 张景波. 交通基础设施建设对产业结构转型的影响研究. 云南财经大学学报, 2018, 34(11): 37-48. [ZHANG J B. Research on the impact of transportation infrastructure construction on industrial structure transformation. Journal of Yunnan University of Finance and Economics, 2018, 34(11): 37-48.]

[26] 路畅, 王媛媛, 于渤, 等. 制度环境、技术创新与传统产业升级: 基于中国省际面板数据的门槛回归分析. 科技进步 与对策, 2019, 36(14): 62-68. [LU C, WANG Y Y, YU B, et al. Institutional environment, technological innovation and 
traditional industrial upgrading: A threshold test based on interprovincial panel data in China. Science \& Technology Progress and Policy, 2019, 36(14): 62-68.]

[27] 袁航, 朱承亮. 国家高新区推动了中国产业结构转型升级吗. 中国工业经济, 2018, (8): 60-77. [YUAN H, ZHU C L. Do national high-tech zones promote the transformation and upgrading of China's industrial structure. China Industrial Economics, 2018, (8): 60-77.]

[28] 侯鹏, 刘思明, 建兰宁. 创新环境对中国区域创新能力的影响及地区差异研究. 经济问题探索, 2014, (11): 73-80. [HOU P, LIU S M, JIAN L N. The influence and its regional difference of innovative milieu on innovation ability in China. Inquiry into Economic Issues, 2014, (11): 73-80.]

[29] 张树静, 张秀峰. 城市创新环境对产学研合作创新的影响. 中国科技论坛, 2018, (4): 25-32. [ZHANG S J, ZHANG $\mathrm{X}$ F. Impact of urban innovation environment on the performance of industry-university-research institute collaborative innovation. Forum on Science and Technology in China, 2018, (4): 25-32.]

[30] 易信, 刘凤良. 金融发展与产业结构转型: 理论及基于跨国面板数据的实证研究. 数量经济技术经济研究, 2018, 35 (6): 21-39. [YI X, LIU F L. Financial development and structure transformation. The Journal of Quantitative \& Technical Economics, 2018, 35(6): 21-39.]

[31] 张勇, 蒲勇健. 产业结构变迁及其对能源强度的影响. 产业经济研究, 2015, (2): 15-22. [ZHANG Y, PU Y J. Industrial structure evolution and its impact on energy intensity. Industrial Economics Research, 2015, (2): 15-22.]

[32] 时乐乐, 赵军. 环境规制、技术创新与产业结构升级. 科研管理, 2018, 39(1): 119-125. [SHI L L, ZHAO J. Environmental regulation, technological innovation and industrial structure upgrading. Science Research Management, 2018, 39 (1): 119-125.]

[33] 张媛媛, 谢林林. 新常态下产业结构转型与人力资源需求的动态变化. 发展研究, 2015, (11): 74-79. [ZHANG Y Y, XIE L L. The changes of demand for human resources from industrial structure transformation. Development Research, 2015, (11): 74-79.]

[34] 付凌晖. 我国产业结构高级化与经济增长关系的实证研究. 统计研究, 2010, 27(8): 79-81. [FU L H. An empirical research on industry structure and economic growth. Statistical Research, 2010, 27(8): 79-81.]

[35] 干春晖, 郑若谷, 余典范. 中国产业结构变迁对经济增长和波动的影响. 经济研究, 2011, (5): 4-15. [GAN C H, ZHENG R G, YU D F. An empirical study on the effects of industrial structure on economic growth and fluctuations in China. Economic Research Journal, 2011, (5): 4-15.]

[36] 王冠孝,梁留科, 李锋, 等. 区域旅游业与信息化的耦合协调关系实证研究. 自然资源学报, 2016, 31(8): 1339-1350. [WANG G X, LIANG L K, LI F, et al. An empirical research on the coupling coordinative relationship between regional tourism and informationization. Journal of Natural Resource, 2016, 31(8): 1339-1350.]

[37] 姜磊, 柏玲, 吴玉鸣. 中国省域经济、资源与环境协调分析: 兼论三系统耦合公式及其扩展形式. 自然资源学报, 2017, 32(5): 788-799. [JIANG L, BAI L, WU Y M. Coupling and coordinating degrees of provincial economy, resources and environment in China. Journal of Natural Resources, 2017, 32(5): 788-799.]

[38] 郭艳军, 叶鹰. 主成分分析在确定贝叶斯网络参数中的应用. 湖北工业大学学报, 2009, 24(1): 73-75. [GUO Y J, YE Y. Using principal component analysis to calculate parameter in Bayesian networks. Journal of Hubei University of Technology, 2009, 24(1): 73-75.]

[39] 刘耀涁, 李仁东, 宋学锋. 中国城市化与生态环境耦合度分析. 自然资源学报, 2005, 20(1): 105-112. [LIU Y B, LI R D, SONG X F. Analysis of coupling degrees of urbanization and ecological environment in China. Journal of Natural Resource, 2005, 20(1): 105-112.]

[40] 刘传明, 张义贵, 刘杰, 等. 城市综合交通可达性演变及其与经济发展协调度分析. 经济地理, 2011, 31(12): 20282033. [LIU C M, ZHANG Y G, LIU J, et al. Study on the evolution of the city's comprehensive transportation accessibility and the coordination degree with the economic development: The empirical research about Huaian since 1991. Economic Geography, 2011, 31(12): 2028-2033.]

[41] 刘浩, 张毅, 郑文升. 城市土地集约利用与区域城市化的时空耦合协调发展评价: 以环渤海地区城市为例. 地理研 究, 2011, 30(10): 1805-1817. [LIU H, ZHANG Y, ZHENG W S. Evaluation on spatio-temporal development and interaction of intensive urban land use and urbanization: Case studies of the cities in the Bohai Rim region. Geographical Research, 2011, 30(10): 1805-1817.]

[42] 冯江茹, 范新英. 资源型地区产业结构优化测度及对经济增长的影响: 以山西省为例. 中国科技论坛, 2015, (9): 9296. [FENG J R, FAN X Y. The measure of industrial structure optimization and effects on economic growth: A case study of Shanxi province. Forum on Science and Technology in China, 2015, (9): 92-96.] 


\title{
Spatial coupling of innovative milieu and industrial structure transformation of resource-based cities in Shanxi province
}

\author{
JIANG Hai-ning ${ }^{1,2}$, ZHANG Wen-zhong ${ }^{2}$, YU Jian-hui' ${ }^{2}$ ZHANG Jian-wei ${ }^{3}$ \\ (1. College of Geography and Environmental Sciences, Zhejiang Normal University, Jinhua 321004, Zhejiang, \\ China; 2. Key Laboratory of Regional Sustainable Development Modeling, Institute of Geographic Science and \\ Natural Resources Research, CAS, Beijing 100101, China; 3. School of Resources, Environment and Tourism, \\ Anyang Normal University, Anyang 455000, Henan, China)
}

\begin{abstract}
In order to analyze the spatial coupling of innovative milieu and industrial structure transformation of resource-based cities in Shanxi province in 2003 and 2016, the coupling coordination degree model was adopted in this paper. The results showed that the quality superiority of innovative milieu about resource- based cities in Shanxi province was changed in different degrees. Among them, the level of innovative milieu with high quality superiority plunged, while the level of innovative milieu with medium quality superiority was rising steadily. The low level innovative milieu, by contrast, did not realize a breakthrough rising at all as time goes on. The degree of industrial structure advancement was increasing, while the degree of industrial structure rationalization was high and relatively complex. The coupling degrees between the original innovative milieu and industrial structure transformation, including industrial structure advancement and industrial structure rationalization, were all high. Therefore, all of the resource-based cities in Shanxi province belonged to high degree coupling regions at this moment. What's more, the coupling degree between the original innovative milieu and industrial structure transformation in most of the cities was going down gradually as time goes on. However, the degrees of coordinated development between innovative milieu and industrial structure advancement, industrial structure rationalization were relatively low. The general pattern of the coordinated development degree in Shanxi province was "north-south moderate imbalance, the middle extreme imbalance" having not changed significantly; Relative development index in most of cities of Shanxi province showed a upward trend. The "north-south" area of Shanxi province belonged to the innovative milieu exorbitant type or simultaneous development between innovative milieu and industrial structure transformation, while the "middle" area mainly belonged to the lagging- type development of innovation milieu. Therefore, we should fully rely on the advantages of existing innovative milieu and industrial structure restructuring ability in every city, guiding the construction and development of resource-based cities according to local conditions, so as to achieve a coordinated and hand-in-hand development of innovative milieu and industrial restructuring.
\end{abstract}

Keywords: innovative milieu; industrial structure transformation; spatial coupling; resourcebased cities; Shanxi province 